\title{
Study on the Coordination Performance of Urban and Rural Construction Land Use in Chengdu City
}

\author{
Xiu-lin SI \\ Department of Economic Management, Sichuan Agricultural University \\ Xingkang road 46, Yaan 625014, Sichuan, China \\ Tel: 86-151-8121-5465Ｅ-mail: 466534sixiulin@163.com \\ Wen-xiu ZHANG \\ Department of Economic Management, Sichuan Agricultural University \\ Xingkang road 46, Yaan 625014, Sichuan, China \\ Tel: 86-133-0816-1528Ｅ-mail: zwx<cndzwx@163.com> \\ Wen-jie Li \\ Department of Economic Management, Sichuan Agricultural University \\ Xingkang road 46, Yaan 625014, Sichuan, China \\ Tel: 86-138-8244-0258_E-mail: liwenjie508@163.com
}

\begin{abstract}
On the basis of defining the concept of coordinating urban and rural construction land use, this paper studied the coordination performance from two aspects, one was the dynamic balance index and the other was the coordination index. The results showed that: the coordination performance of the urban and rural construction land use was high in protecting cultivated land, and also was an important way to protect cultivated land; the coordination index of urban and rural construction land mainly located between 0.4 and 0.6 , the internal structure of urban and rural construction land was unreasonable, the process of land urbanization lagged behind the process of population urbanization, which showed a downward trend and implied there was a large room for improving the performance.
\end{abstract}

Keywords: Construction land, Performances, Coordination of urban and rural, Cultivated land protection, Chengdu city

\section{Introduction}

With high-speed development of economic, especially rapid industrialization and urbanization, the problem of cultivate land protection becomes more and more serious in china, the limited arable land resource is facing the demand pressures from urban and rural construction, and many other aspects(Lu,2008), the contradiction between economic development and arable land protection is increasingly prominent. According to the national survey of land resources, the area of rural residential land reached 14.7 million $\mathrm{hm}^{2}$, the per capita area reached $182 \mathrm{~m}^{2}$, the distribution of rural construction land was more scattered, "empty villages" was abound, land use was extensive with serious waste of land resources. The face of how to coordinate the relationship between cultivated land protection and economic development, and improve the intensive level of land use, some scholars proposed coordinating urban and rural construction land in the current context of urban and rural development. Coordinating urban and rural construction land is not only a objective requirement of balancing urban and rural development, but also an important way to protect arable land and optimize allocation of construction land between urban and rural areas. And its coordination performance is an important symbol to measure the coordination level of urban and rural construction land use; therefore, the study on the performance has great significance. With the goal of coordinating urban and rural construction land use, this article studied the coordination performance of the urban and rural construction land in Chengdu city from two aspects, one was the dynamic balance of the urban and rural construction land and cultivated land, another was the coordination degree of urban and rural construction land. 


\section{Content of coordinating urban and rural construction land}

Coordinating urban and rural construction land takes optimizing resource allocation and coordinating industrial development as the goals, takes the urban and rural construction land as a whole to overall planning according to the needs of urban and rural economic development, so that construction land can be used in the two-way interaction and coordinated operation between urban and rural areas, finally achieves Pareto optimal of the use of land resources (Li, 2004; Zhao, 2008). Coordinating urban and rural construction land use includes overall planning for land elements, overall planning for land policy, and overall planning for land market, the former is the ultimate goal of the latter two, both of the latter is the premise of the former. In this paper, we study on the overall planning for land elements of the urban and rural construction land. At present, the main way to coordinate urban and rural construction land is linked to changes in urban and rural construction land. Linked to changes in urban and rural construction land is a land consolidation to ultimately realize that the total amount of construction land does not increase, the total amount of cultivated land and it's quality does not reduce, land distribution more reasonable in the context of overall planning for urban and rural development, by formatting the project areas with the number of rural construction land to be reclaimed for rural land and the number of the plots to be used for building cities and towns according to land use planning.

\section{Evolution analysis of construction land in Chengdu}

\subsection{General introduction of Chengdu}

Chengdu is located in the eastern of Chengdu Plain, with the plain landscape and fertile soil. She comprises 19 districts (cities, counties), with the total area 1.24 million $\mathrm{hm}^{2}$. In 2008, the city's GDP reached 390.2 billion RMB, up 15.3 percent over the previous year, and the per capita output value reached 26,527 RMB. According to the statistics of detailed survey of land use in 2006, the total area of rural construction land in Chengdu reached 92,700 hectares, accounting for 48 percent of the total area of construction land, $90 \%$ of which was house site, per capita rural construction land area reached $154 \mathrm{~m}^{2}$. If the area of per capita rural house site was reduced to $70 \mathrm{~m}^{2}$, the city can increase 43,300 hectares reserve urban construction land. In 2003, Chengdu promoted the coordination of urban and rural development at the core of three concentrations that industry concentrate in development areas, land concentrate in scale operation and the peasant concentrate in cities and towns. The main line of the "three concentration" mechanism is coordinating urban and rural construction land to promote more intensive utilization of land ( $\mathrm{Wu}, 2008)$. And in June 7, 2007, Chengdu was approved as "a national comprehensive coordinated reform trial place" with Chongqing by the State Council officially, was another national comprehensive reform pilot area following the Pudong New Area of Shanghai and Binhai New Area of Tianjin. According to the statistics, a large number of projects of linked to changes in urban and rural construction land were declared. From 2005 to 2007, the number of these projects reached 15, with $465.4 \mathrm{hm}^{2}$ linked circulating target and the area of urban construction land reached $355.4 \mathrm{hm}^{2}$.(CRG,2008)

\subsection{Evolution analysis on the quantitative of cultivated land and urban construction land in Chengdu}

Urban construction land includes urban land, land for towns, independent mining land and transportation land. For the area of the transportation land has a lesser extent change, this article selected the first three as urban construction land to study. Rural construction land was composed of the rural residential land, rural mining land, and abandoned brick field. Since the transformation of the rural economy and rural construction land consolidation, rural mining land and abandoned mines have little space to consolidate. The consolidation space of rural construction land mainly concentrate in the rural residential land in the future, so this paper takes the rural residential land as rural construction land to study.

From 1998 to 2007, the area of arable land in Chengdu decreased from $489715.9 \mathrm{hm}^{2}$ to $424069.1 \mathrm{hm}^{2}$, down 13.4 percent; the area of urban and rural construction increased from $142229.1 \mathrm{hm} 2$ to $173907.2 \mathrm{hm} 2$, up 22.27 percent. Figure 1 showed that the trend of arable land reduction was basically the same with the increasing trend of urban and rural construction land, the Pearsonion correlation coefficient of both was -0.967 through the SPSS software, showing a high degree of negative correlation, this showed that the deduction of cultivated land area in Chengdu was due mainly to expansion of the urban and rural construction land. Figure 1 showed the decrease rate of cultivated land in 2005 and the increase speed of urban construction land decreased obviously in Chengdu, the reason was that Chengdu applied a large number projects of linked to changes in urban and rural construction land in 2005. These projects linked the increase of urban construction land to the reduction of rural construction land construction land, made good use of land reserves to keep the quantity of farmland in a dynamic balance.

\subsection{Evolution analysis of the structure of the Urban and Rural Construction Land}

Whether the structure of urban and rural construction land is reasonable has a significant impact on the urban 
and rural economic development, the scientific and reasonable structure of construction land use between urban and rural areas is an important goal of coordinating urban and rural construction land. With economic development and urbanization process, the use structure of urban and rural construction land also changed constantly, the level of land urbanization (Guo, 2007) was also rising. It can be seen from figure 2 that the proportion of rural residential land has been declining from 65.5 percent in 1998 to 52.22 percent in 2007, and an average annual decrease rate reached 1.33 percent in Chengdu. The rural residential land took a large proportion in construction land, though in the past 10 years, the proportion declined, but the declined speed was slower. The urban land increased from $21383.9 \mathrm{hm}^{2}$ in 1998 to $37710.95 \mathrm{hm}^{2}$ in 2007 , the proportion increased from 15 percent to 22.7 percent, showing an average annual growth of 0.77 percent. The town land increased from 8.1 percent in 1998 to 14.6 percent in 2007, showing an average annual growth of 0.65 percent. The proportion change of mining land twisted and turn, and with smaller amplitude. The increasing degree of the urban land proportion was larger than the towns, which showed Chengdu took a bit central city as the model of development.

\section{Performance analysis of coordinating Urban and Rural Construction Land}

\subsection{Analysis of the dynamic equilibrium between urban and rural construction land and farmland}

Arable land protection is an important goal of coordinating urban and rural construction land use, and should be one of the indicators of measuring its performance. In the process of coordinating urban and rural construction land use, the part of arable land is translated into construction land, and new arable is reclaimed by the rural residential land arrangement, so there is increase and decrease of cultivated land, the increase of urban construction land and reduction of rural construction land. This article defines the dynamic balance index (DBI) to study the dynamic changes of urban and rural construction land.

$$
D B I=\frac{\Delta s_{+}-\Delta s_{-}}{\Delta s_{+}+\Delta s_{-}}
$$

$\Delta s_{+}$denotes the increase area, $\Delta s_{-}$denotes the deduction area. The value range of DBI is[-1,1], the max value denotes only increase, the min value denotes only deduction, the more dynamic level index close to 0 indicates that the closer the dynamic balance.

Figure 3 showed the dynamic balance degree was in the trend of increase in the overall, and was roughly divided into two stages 1998-2004 and 2005-2007. From 1998 to 2004, the absolute value of dynamic balance index were greater, that expressed the dynamic balance of both were poor, and the dynamic balance index of urban and rural construction land was greater than the cultivated land. The main reason was the continued expansion of construction land and the rapid decrease of cultivated land during this period. From 2005 to 2007, the dynamic balance index value of the both were relatively close to the axis, that indicated the arable land and urban and rural construction land closed to dynamic balance during this period. This also explained that the policies of linked to changes in urban and rural construction land from 2005 had a dramatic impact on the dynamic balance of cultivated land, and the expansion of urban construction land has also been effectively controlled in recent years. The dynamic balance degree of the construction land was lower than the arable land that indicated that urban and rural construction land occupied other types of land apart from farmland in recent three years.

\subsection{Analysis of internal coordination of urban and rural construction land}

Because of the different modes of production between urban and rural areas, urban and rural residents have different demand of living space. In order to eliminate the impact of different production methods, a conversion coefficient was set up to compare per capital area of urban construction land with rural construction land. According to the classes of urban land and the use planning standards of construction land, the upper limit of per capita area of urban construction land is $120 \mathrm{~m}^{2}$. According to the use planning standards of rural residential land the upper limit of per capita area of rural residential land is $150 \mathrm{~m}^{2}$ at the corresponding time period. From these two standards, we can know that the area demand of construction land are different between urban and rural area, therefore, we took 1.25 the ratio of the both as the conversion coefficient. This paper used the coordination index of Urban-rural construction land (Wang, 2008) to further study the coordination of urban and rural construction land.

$$
U R C L H I=P_{u} * 1.25 / P_{r}
$$

$P_{u}$ stands for per capita area for urban construction land, and $P_{r}$ stands for per capita area of rural construction land. The value of URCLHI gets closer to 1 , the more coordinated the use of construction land between urban and rural area is, Less than 1 indicated per capita area of the rural residential area is too large, greater than 1 indicated per capita area of the urban construction land area is too large. 
According to the above definition, we can analyze of the coordination of urban and rural construction land from 1998 to 2007 in Chengdu. Figure 4 showed the coordination index of urban and rural construction land concentrated in between 0.4 and 0.6. It reached the max in 2003 and the min in 2005, and the overall trend was descendent during the past 10 years that indicated the coordination of construction land use was poor between urban and rural area, the rural resident land was too large obviously. The main reason was that with the accelerated process of urbanization, the increase of urban population, and decrease of rural population, the area of rural residential land did not decrease, resulting in the per capita area of the construction land in rural areas continuing to rise. The resistance was huge in the process of integrating urban and rural construction land, as the rural residential land consolidation led to the problem of property right adjustment. A lot of money also is needed, so fund shortage is a limiting factor since Chengdu took the government leading style. Therefore, Chengdu should increase efforts to make the falling speed correspond between rural residential consolidation and rural population. On the basis of the analysis and evaluation of the consolidation of rural residential area, Chengdu should implement the measures and step up efforts to integrate urban and rural construction land and build a sound interaction with each other.

\section{Conclusions}

Coordinating Urban and rural construction land is an important channel for arable land protection and intensive and efficient use of land, is an objective requirement to balance urban and rural development and achieve "five balances". In this paper, we took Chengdu as an example to analysis the overall performance of urban and rural construction land and drawn the following conclusions:

(1) Most of the reduced cultivated land was occupied by urban construction land; the main source of increasing cultivated land was rural residential land consolidation. The change trends of cultivated area in Chengdu gradually began to become dynamic balance from 1998 to 2007. In particular, since a lot of the projects of linked to changes in urban and rural construction were carried out; the area of arable land has basically kept in a dynamic balance. Therefore, coordinating urban and rural construction land in Chengdu not only achieved a higher performance on protecting arable land, but also met the land demand for economic development. To sum up, coordinating urban and rural construction land is an effective way to protect arable land, but also an inevitable choice.

(2) Coordinating urban and rural construction land in Chengdu achieved remarkable results in the protection of cultivated land, but the allocation performance of urban and rural construction land still remained to be improved. First of all, the area of urban and rural construction land continued to expand in Chengdu, the dynamic balance index of urban and rural construction land was always greater than 0. Secondly, the internal structure of urban and rural construction land was inconsistent, no matter from the total area of construction land or per capita area of construction land. From 1998 to 2007, the coordination index of urban and rural construction land was between 0.4 and 0.5 in Chengdu, with the downward overall trend. Especially from 2005 to 2007, the coordination index of urban and rural construction land reached the lowest value. From 2004, the level of construction land urbanization lagged behind the level of population urbanization in Chengdu, the chief reason was that the progress of coordinating urban and rural construction land lagged behind the demands from economic development. Given all that, the performance of coordinating urban and rural construction land in Chengdu was not high on optimizing the allocation of urban and rural construction. The main causes were concluded as follow: the land use system of urban and rural construction land was irrational, the market of urban and rural construction land was imperfect that restricted the process of coordinating urban and rural construction land, while coordinating urban and rural construction land has a large capital demand, lack of fund is the bottleneck of integrating urban and rural construction land. In the context of balancing urban and rural development, how to realize overall planning on urban and rural construction land still needs further research.

\section{References}

Caiyun Zhao. (2008). Coordination Urban and Rural Development and its' influential factors in China. Doctoral dissertation, Chinese Academy of Agricultural Sciences.

Chunyang Lu, Qinyuan Yang, Feng Wen \& Zhang yantao. (2008). Empirical Analysis of relationship between the area change of cultivated land and economic development in Chongqing. Southwest University journal (natural science edition), pp: 146-151.

Jianlin Wu. (2008). Ideal logic of the three concentrations - second rural areas of Chengdu in the process of industrialization, [Online] Available: http://blog.sina.com.cn.

National technology supervise office, Ministry of Construction of PRC and the States jointly issued, National 
Standard of the People's Republic of China $<$ Town Planning Standard $>$.

Research Group of Chengdu Bureau of State Land Inspect. (2008). The analysis and suggestion of Innovation of Rural Land Institution in reform experimental zones of urban and rural in Chengdu.China Land.

Shengwu Wang. (2008). The study on coordinating urban and rural construction land in Jinan city. Shandong Normal University, pp, 04

The Ministry of Construction the People's Republic of China. (1991). Urban land classes and the standard of planning and construction land (GBJ137-90). China plan press.

Wenhua Guo \& Jinming Hao. (2005). The study of the evaluation index of urban construction land in the process of urbanization. resource science, pp, 27(3):66 - 71 .

Yueyun Li, Yong Chen \& Lin Sun. (2004). Overall planning of urban and rural and it's method. Agriculture technology economic, pp: 24-30.

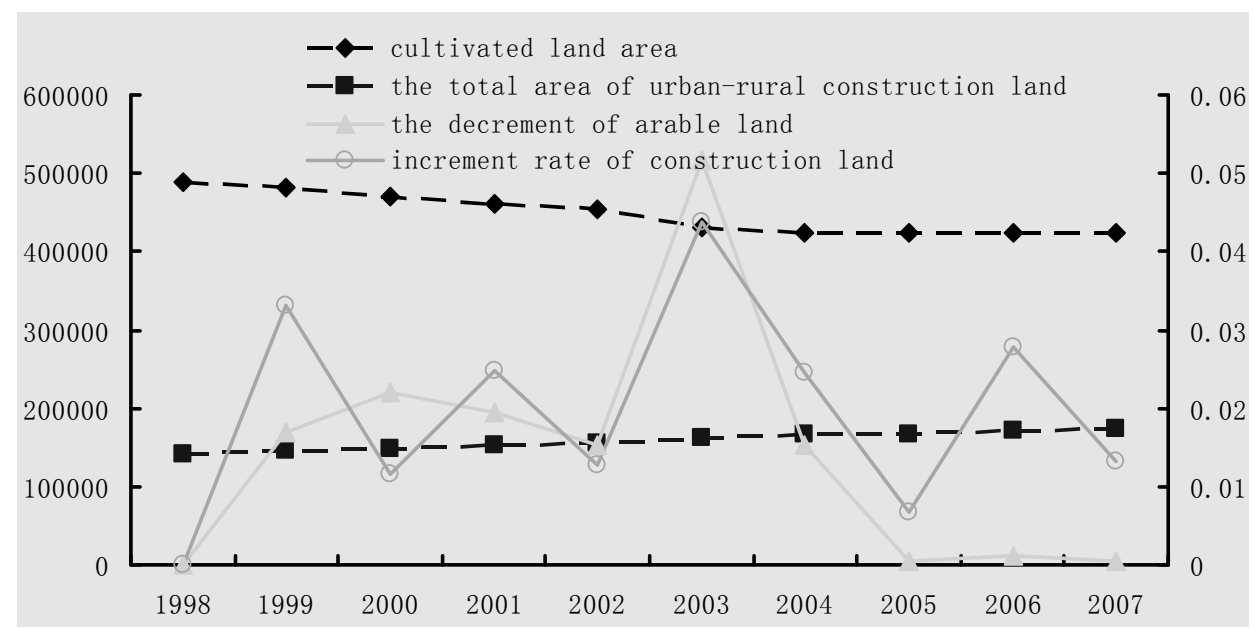

Figure 1. The area evolution of arable land and urban -rural construction land from 1998 to 2007 in Chengdu unit: $\mathrm{hm}^{2}$

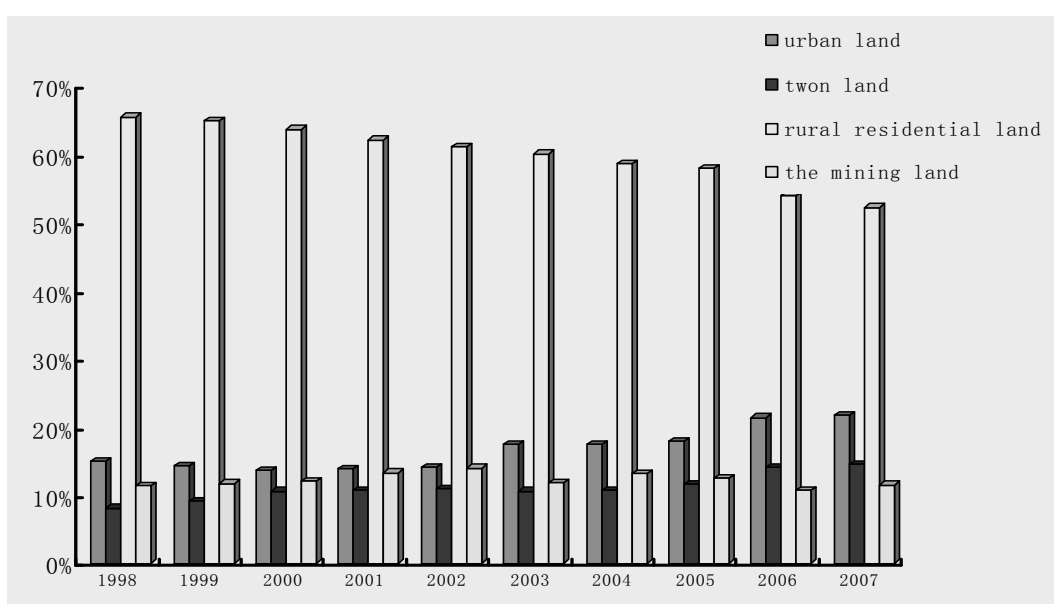

Figure 2. The area evolution of urban -rural construction land from 1998 to 2007 in Chengdu 


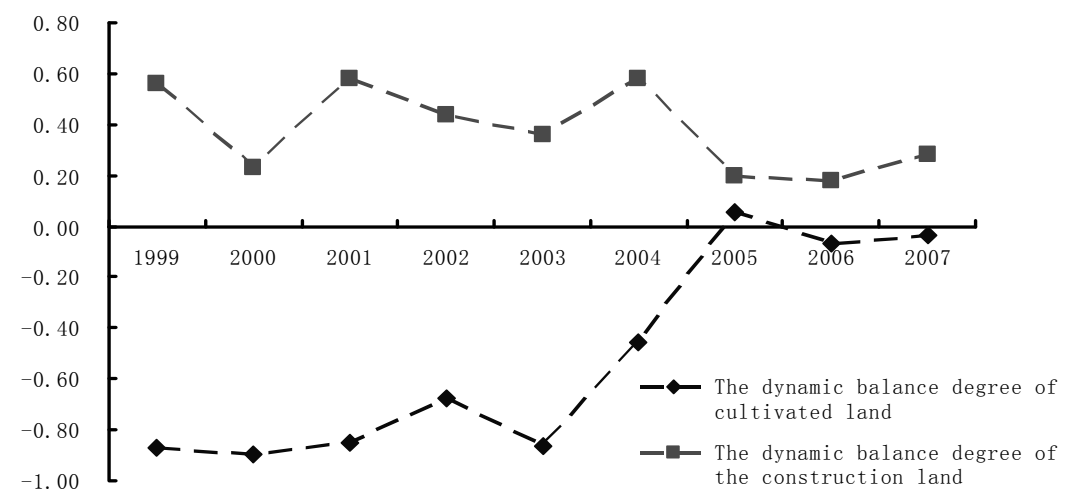

Figure 3. The dynamic balancing degree of arable land and urban -rural construction land from 1998 to 2007 in Chengdu

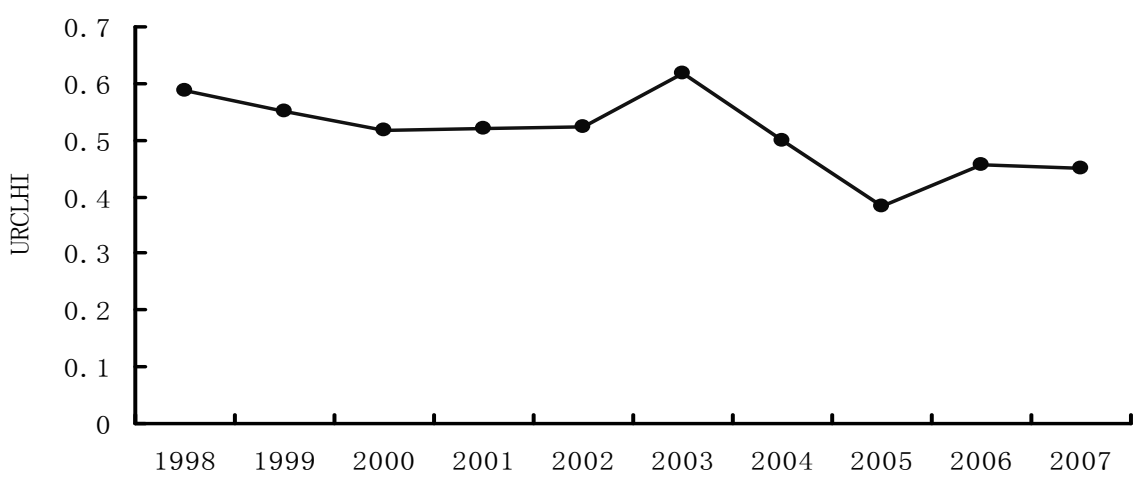

Figure 4. Urban-rural construction land harmonizing index from 1998 to 2007 in Chengdu 